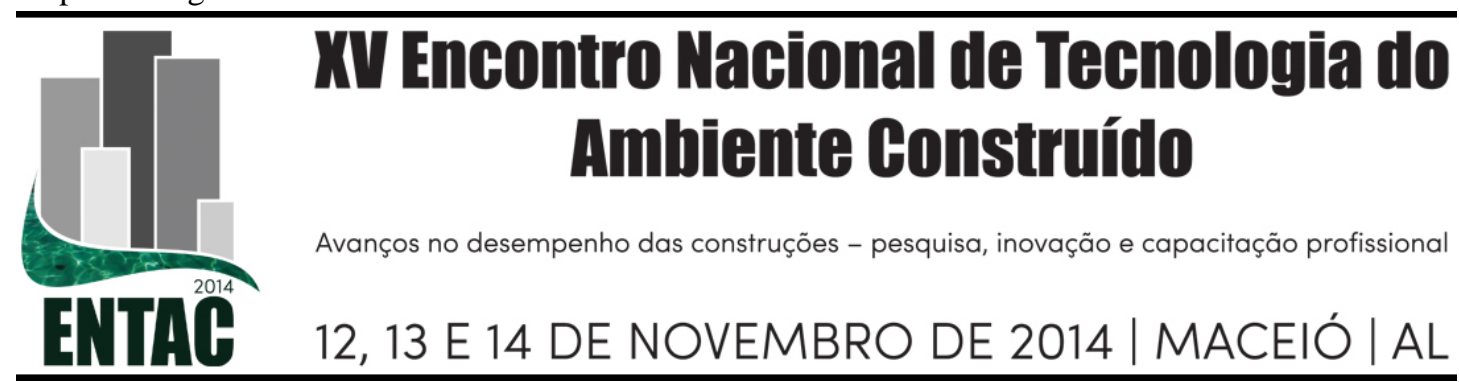

\title{
ARQUITETURA CONTEMPORÂNEA NA HABITAÇÃO SOCIAL EM SÃO PAULO: O CONJUNTO MATA VIRGEM
}

\author{
VERAS, Mariana Ribeiro (1); PISANI, Maria Augusta Justi (2) \\ (1) Universidade Presbiteriana Mackenzie, 2114-8298, marianarveras@gmail.com (2) Universidade \\ Presbiteriana Mackenzie, (11) 99187-3437, augustajp@gmail.com
}

\begin{abstract}
Neste século a sustentabilidade deixou de ser um tema apresentado preponderantemente no campo teórico e passa a ser prático e aplicado na arquitetura e no urbanismo. Considerando que a habitação é o uso mais recorrente das edificações brasileiras e que nosso déficit habitacional ultrapassa a casa dos seis milhões de unidades, a sustentabilidade nestes empreendimentos se torna um tema de relevância social, econômica, cultural, política e ambiental. O objetivo desta investigação é analisar o Conjunto Mata Virgem, projeto do arquiteto José Luiz Tabith Junior, aplicando critérios de análise da sustentabilidade em habitação de interesse social vinculados ao Programa de Urbanização de Favelas do Município de São Paulo. Esta pesquisa, de caráter exploratório, realiza diversos estudos de caso dos conjuntos habitacionais de interesse social produzidos no século XXI. Os procedimentos metodológicos deste trabalho envolvem as etapas tais como: coleta de dados secundários com ênfase nos quesitos da certificação Selo Casa Azul da Caixa Econômica Federal; estudo de caso do conjunto habitacional Mata Virgem por meio de levantamentos de dados primários, incluindo visitas "in loco" e entrevista com o arquiteto autor do projeto. Os resultados obtidos apontam qualidades do projeto, como por exemplo, as melhorias no entorno do conjunto com a instalação de infraestrutura, na geração de emprego e renda aos moradores locais e na parceria entre a Prefeitura e o Governo do estado de São Paulo para a produção de habitação social; porém também indicam outras possibilidades que poderiam ter fornecido mais sustentabilidade ao conjunto e que não foram empregadas, como por exemplo, o aproveitamento de águas pluviais e o aquecimento de água por energia solar.
\end{abstract}

Palavras-chave: Selo Casa Azul da CAIXA, habitação social sustentável, Conjunto Mata Virgem.

\section{ABSTRACT}

In this century sustainability is no longer an issue presented predominantly in theoretical and practical, and shall be applied in architecture and urbanism. Considering that housing is the recurrent use of the buildings and our Brazilian housing deficit exceeds the home of six million units, sustainability these projects becomes a subject of social, economic relevance, cultural, political and environmental. The objective of this research is to analyze the "Conjunto Mata Virgem" by architect José Luiz Tabith Junior project applying sustainable criteria in social housing linked to Slum Upgrading Program of São Paulo . This research, exploratory and performs several case studies of housing of social interest produced in the XXI century. The methodological procedures of this study involve steps such as secondary data collection with emphasis on questions of accreditation "Selo Casa Azul da Caixa Economica Federal"; case study of the housing Virgin Forest through surveys of primary data, including visits "in loco" and interview with the author of the project architect. Results indicate qualities of the project, such as improvements in the vicinity of the set with the installation of infrastructure, generation of employment and income for local residents and partnership between the City and the Government of the State of São Paulo for the production of social housing, but also indicate other possibilities that could have provided more sustainability and to all who were not employed, for example, rainwater harvesting and water heating by solar energy.

Keywords : Selo Casa Azul da CAIXA, sustainable social housing , Conjunto Mata Virgem, ENTAC 2014. 


\section{INTRODUÇÃO}

Como o uso habitacional é o mais frequente nas edificações brasileiras e o déficit habitacional brasileiro excede o número de seis milhões de unidades, a sustentabilidade nestes empreendimentos se torna um tema de relevância social, econômica, cultural, política e ambiental. O objetivo desta pesquisa é de: analisar o emprego de critérios sustentáveis em habitação de interesse social vinculados ao Programa de Urbanização de Favelas do município de São Paulo a partir dos critérios de avaliação propostos pelo manual Selo Casa Azul da Caixa Econômica Federal, tendo como estudo de caso o conjunto Mata Virgem na cidade de São Paulo.

Os procedimentos metodológicos empregados para o desenvolvimento deste trabalho seguiu as etapas de: coleta de dados secundários e análise crítica de material consultado e o estudo de caso com roteiro de análise fundamentado no Manual Selo Casa Azul da Caixa Econômica Federal. Os quesitos avaliados foram: qualidade urbana; projeto e conforto; eficiência energética; conservação de recursos materiais; gestão da água e as práticas sociais. A entrevista com o arquiteto José Luiz Tabith Jr., autor do projeto, e os levantamentos de campo embasaram as análises. Para a avaliação da qualidade da iluminação natural foram elaboradas simulações, com o emprego do software Relux Professsional 2000. Os resultados parciais deste trabalho juntamente com os demais produzidos pelo grupo de pesquisa "Arquitetura e Construção" da Faculdade de Arquitetura e Urbanismo da Universidade Presbiteriana Mackenzie alimentam um repertório pré-existente e fundamentam novas discussões sobre como produzir habitação social no Brasil.

\subsection{Urbanização de favelas na cidade de São Paulo}

Em 2005, a Prefeitura de São Paulo lançou o Programa de Urbanização de Favelas, visando melhoria e a instalação de infraestrutura básica nos assentamentos precários que não apresentassem necessidade de remoção, além disso, proporcionar novas habitações para as famílias desalojadas. O programa, ainda em vigor, representa o maior suporte de regularização urbanística e fundiária do Brasil e já promoveu melhorias em várias favelas da cidade, como: Paraisópolis, Heliópolis, Jardim São Francisco, Cantinho do Céu, Jaguaré e outras. O Programa de Urbanização de Favelas apresentava

[...] como foco a urbanização e a regularização fundiária de áreas degradadas, ocupadas desordenadamente e sem infraestrutura. O objetivo é transformar favelas e loteamentos irregulares em bairros, garantindo a seus moradores o acesso à cidade formal, com ruas asfaltadas, saneamento básico, iluminação e serviços públicos (SÂO PAULO, 20--, s/p).

A partir da ideia de urbanização, são desenvolvidos projetos para áreas específicas que tem como base teórica "promover a qualificação urbana e habitacional de núcleos de favelas ou assentamentos precários [...] com provisão de soluções habitacionais na própria área de intervenção"; ou seja, além de melhorias urbanas, a construção de conjuntos habitacionais também se apresenta como prioridade a fim de minimizar o déficit habitacional e proporcionar moradias adequadas a essa parcela da população.

De acordo com o Plano Municipal de Habitação de São Paulo (2010), “a moradia digna é entendida $[. .$.$] como vetor de inclusão sócio territorial, que garante a construção da$ cidadania a todos os moradores". 
Entre os anos de 2005 a 2012, dados informam que este programa da Secretaria Municipal de Habitação (Sehab) de São Paulo beneficiou 40 mil famílias em todo município, e objetivava atender aproximadamente mais 134 mil famílias. Este foi contemplado em 2012 com o prêmio Scroll of Honor, da UN-Habitat.

Desde sua implantação, o programa de urbanização de favelas passou por modificações e foi sendo aperfeiçoado algumas vezes, acompanhando as mudanças de estruturação do governo municipal e em determinadas situações sofrendo interferências e atrasos devido a este processo de renovação do poder público. Pisani et al (2013) destaca a boa arquitetura praticada no período de 2008 a 2012 na aplicação das políticas públicas da Prefeitura de São Paulo em urbanização de favelas, entre elas destacam-se os conjuntos: Alexandre Mackenzie na Favela Nova Jaguaré, do arquiteto Marcos Boldarini; os Conjuntos E e F em Paraisópolis, do Arquiteto Edson Elito, o conjunto "Redondinho" em Heliópolis do Arquiteto Ruy Ohtake e o Conjunto Mata Virgem do arquiteto José Luiz Tabith Junior.

\section{CONJUNTO HABITACIONAL MATA VIRGEM}

Projetado pelo escritório do arquiteto José Luiz Tabith Junior, o conjunto habitacional Mata Virgem fica localizado na subprefeitura de Cidade Ademar, próximo da divisa entre as cidades de São Paulo e Diadema. Este residencial foi desenvolvido a partir de uma parceria entre a Prefeitura de São Paulo, por meio da Secretaria Municipal de Habitação (Sehab) e o Estado, pela Companhia de Desenvolvimento Habitacional e Urbano do Estado de São Paulo (CDHU). O projeto faz parte da segunda etapa do Programa de Mananciais da prefeitura de São Paulo que tem como finalidade "recuperar e conservar a qualidade das águas dos reservatórios Guarapiranga e Billings, melhorar as condições de vida dos moradores, e garantir a inclusão social da população e a sustentabilidade das intervenções urbanísticas realizadas por este programa" (SÃO PAULO, 2012).

Este conjunto habitacional tem capacidade para abrigar 9\% das 4.500 famílias previstas para serem assistidas por esta etapa do programa, retiradas de ocupações irregulares na região do Cantinho do Céu e que se encontrava em risco iminente de ocorrência de acidente devido a deslizamentos de terra ou assoreamento na represa. O projeto foi encomendado ao arquiteto em 2008, porém só teve suas obras iniciadas em 2010 e foi concluída e entregue aos moradores em outubro de 2012.

O ponto de partida para o desenvolvimento do projeto foi a preocupação em preservar o meio ambiente, buscando promover o mínimo de intervenção no espaço físico préexistente. $\mathrm{O}$ arquiteto José Tabith Junior desenvolveu toda estrutura do conjunto habitacional levando em consideração o relevo presente e a vegetação já existente no terreno destinado. O projeto concluído apresenta-se formado por 6 blocos, como pode ser visto na figura 1. Essas torres formam 3 condomínios independentes no mesmo terreno, e oferecem um total de 407 apartamentos. As torres possuem no máximo 4 pavimentos acima do nível da rua, para que assim não houvesse a necessidade de instalação de elevadores. 


\section{Figura 1 - Implantação das edificações que compõe o residencial Mata Virgem}



Fonte: Acervo do arquiteto José Luiz Tabith Junior (2012)

Os blocos de apartamento são divididos em módulos que podem ser retirados ou acrescentados de acordo com a disposição no terreno, permitindo assim uma maior facilidade de execução da obra. Os únicos módulos que apresentam diferença são os que ficam situados nas extremidades das edificações e os pavimentos térreos que possuem apartamentos adaptados destinados a pessoas com necessidades especiais e alguns ambientes de uso comum. Em cada bloco, foi projetado no piso térreo um apartamento destinado a pessoas com necessidades especiais, seguindo a porcentagem exigida pela legislação. Além disso, neste mesmo pavimento, cada bloco também apresenta algumas áreas de uso comum e voltadas para o lazer como, sala de jogos, salão de festa e lazer infantil. Os apartamentos possuem uma única tipologia, que segundo o arquiteto fora planejada para ser uma planta flexível que possibilitaria a existência de 2 ou 3 dormitórios. Porém por determinação da Prefeitura fixou-se que todos os apartamentos seriam compostos por 3 dormitórios, 1 banheiro, sala, cozinha e área de serviço, distribuídos em uma área de $42,95 \mathrm{~m}^{2}$. (figura 2 e 3)

A estrutura é feita com blocos de concreto sem a utilização de pilares, ou seja, em alvenaria estrutural. Tabith Jr. (2012) revelou algumas influências que teve ao desenvolver este projeto, relatando que buscou destacar a cobertura na edificação projetando-a como se estivesse solta da construção, e que optou por uma postura arquitetônica influenciada pelo estilo moderno europeu. (figura 4)

Para compor com a arquitetura projetada e buscar uma identidade dos moradores com o local, o arquiteto também desenvolveu painéis artísticos que foram pintados em cada 
bloco de apartamento, optando por identificar cada condomínio com uma cor predominante nestes painéis. (figura 5 e 6 ).

Figura 2 - Blocos

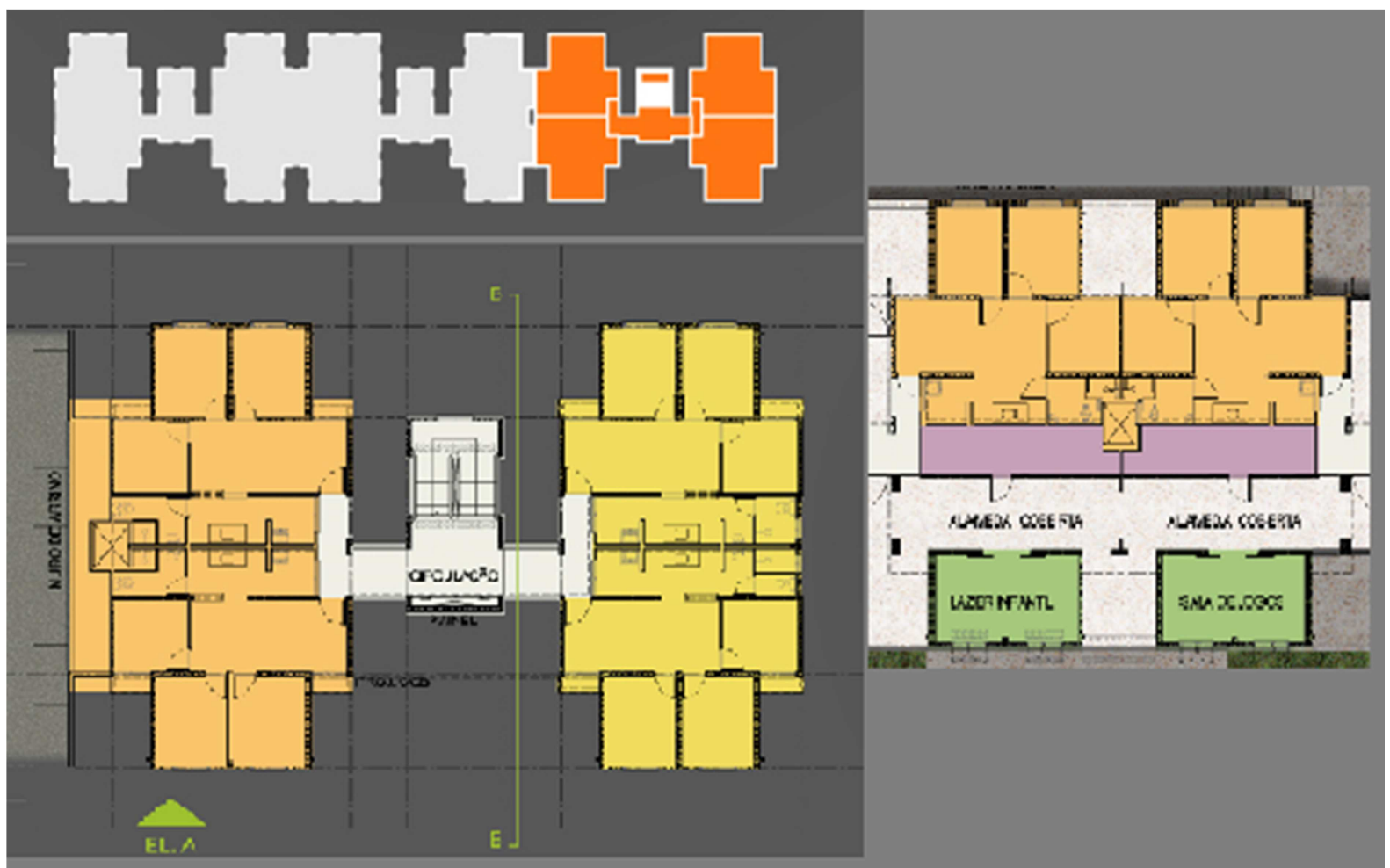

Fonte: Acervo do arquiteto José Luiz Tabith Junior (2012)

Figura 3 - Parte da planta baixa de um pavimento térreo



Fonte: Acervo do arquiteto José Luiz Tabith Junior (2012) 
Figura 4 - Elevação com a rua e o talude.

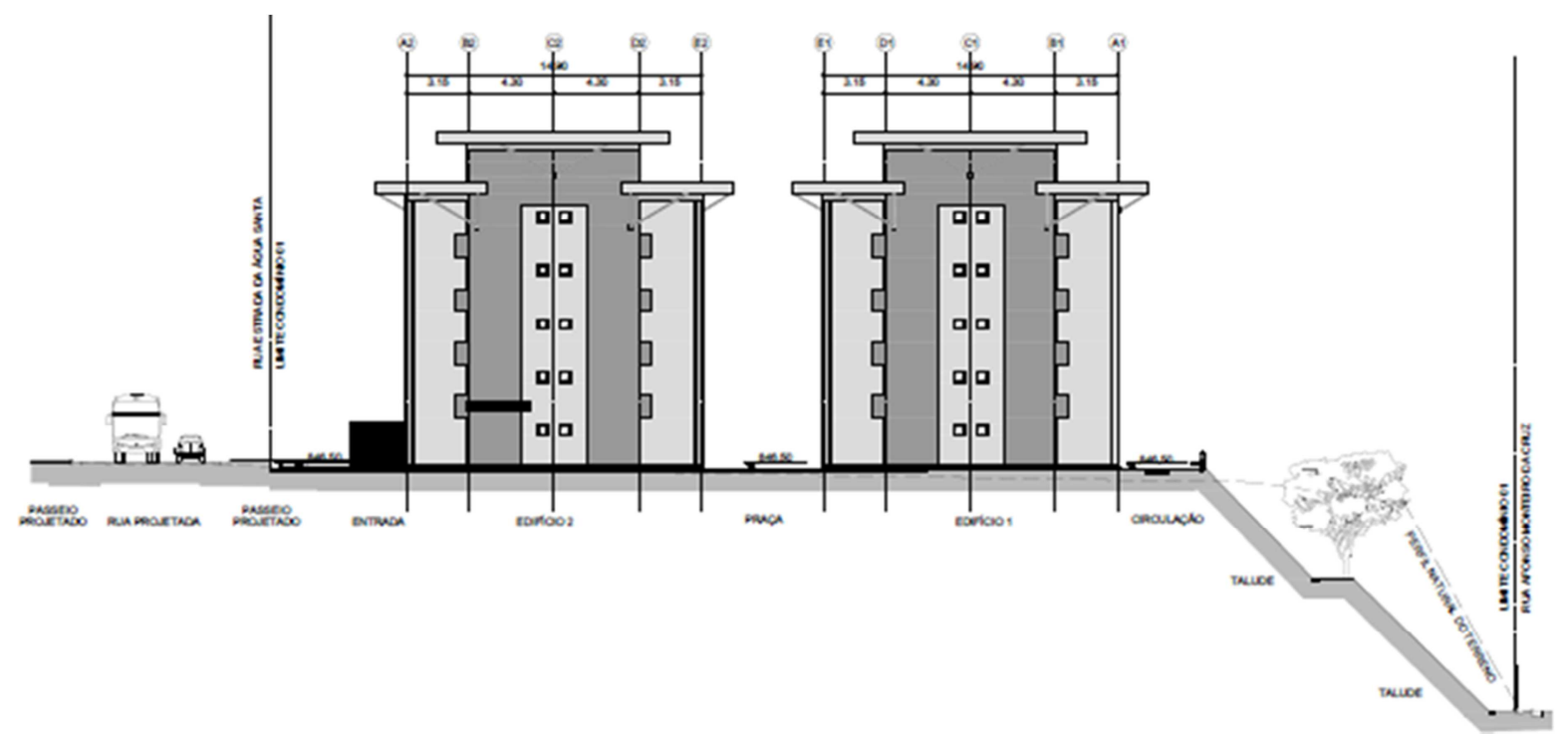

Fonte: Acervo do arquiteto José Luiz Tabith Junior (2012)

Figura 5- Diferentes painéis artísticos para caracterizar cada bloco e Figura 6 -

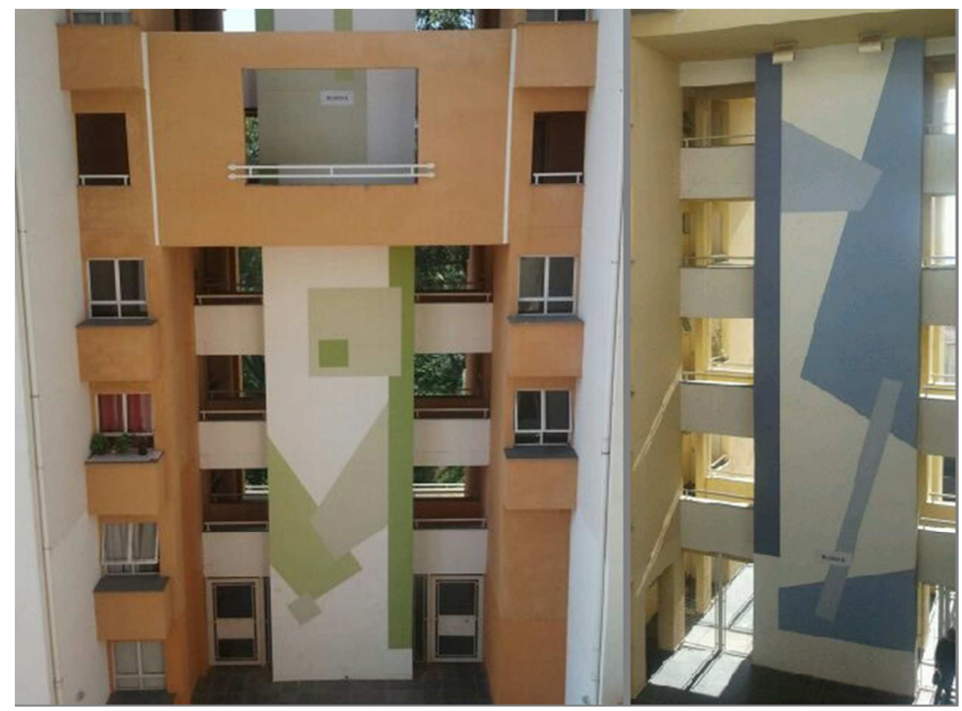

Fonte: Acervo do arquiteto José Luiz Tabith Junior (2012)

\subsection{Análise a partir do Selo Casa Azul da CAIXA}

A análise desenvolvida teve como roteiro base o Selo Casa Azul da CAIXA (BOAS PRÁTICAS PARA HABITAÇÃO MAIS SUSTENTÁVEL, 2010) propiciando uma avaliação da obra em 6 aspectos que abrangem 53 critérios de análise, adotando-se as respostas segundo os seguintes critérios: 
a) Se o quesito é obrigatórios: sim e não;

b) As respostas em cada quesito: sim - quando o conjunto habitacional em análise atender aos requisitos referentes a cada critério exposto; não - quando menos de $50 \%$ das exigências do quesito foram atendidas; parcialmente - diante do cumprimento de mais de $50 \%$ porém não atingiram a totalidade da exigências solicitadas no critério observado e não se aplica - perante um critério de análise que não se adeque ao tipo de edificação ou urbanismo em questão.

A Tabela 1 a seguir apresenta os resultados das análises dos critérios do Selo Casa Azul:

Tabela 1 - Resultados da aplicação dos critérios do Selo Casa Azul da CAIXA no Conjunto Mata Virgem

\begin{tabular}{|c|c|c|c|c|c|}
\hline \multirow{2}{*}{ 1-QUALIDADE URBANA } & \multirow{2}{*}{$\begin{array}{l}\text { Obriga } \\
\text { torio }\end{array}$} & \multicolumn{4}{|c|}{ Existência no Projeto } \\
\hline & & Sim & Não & $\begin{array}{c}\text { Parcial } \\
\text { mente }\end{array}$ & $\begin{array}{l}\text { Não se } \\
\text { aplica }\end{array}$ \\
\hline 1.1 Qualidade do Entorno - Infraestrutura & Sim & $\mathbf{X}$ & & & \\
\hline 1.2 Qualidade do Entorno - Impactos & Sim & $\underline{\mathbf{X}}$ & & & \\
\hline 1.3 Melhorias no Entorno & & $\mathbf{X}$ & & & \\
\hline 1.4 Recuperação de Áreas Degradadas & & $\mathbf{X}$ & & & \\
\hline 1.5 Reabilitação de Imóveis & & & & & $\mathbf{X}$ \\
\hline \multirow{2}{*}{2 - PROJETO E CONFORTO } & \multirow{2}{*}{$\begin{array}{l}\text { Obriga } \\
\text { torio }\end{array}$} & \multicolumn{4}{|c|}{ Existência no Projeto } \\
\hline & & Sim & Não & $\begin{array}{c}\text { Parcial } \\
\text { mente }\end{array}$ & $\begin{array}{l}\text { Não se } \\
\text { aplica }\end{array}$ \\
\hline 2.1 Paisagismo & Sim & $\mathbf{X}$ & & & \\
\hline 2.2 Flexibilidade de Projeto & & & $\mathbf{X}$ & & \\
\hline 2.3 Relação com a Vizinhança & & & & $\mathbf{X}$ & \\
\hline 2.4 Solução Alternativa de Transporte & & & $\mathbf{X}$ & & \\
\hline 2.5 Local para Coleta Seletiva & Sim & $\mathbf{X}$ & & & \\
\hline 2.6 Equipamentos de Lazer, Sociais e Desportivos & Sim & $\mathbf{X}$ & & & \\
\hline 2.7 Desempenho Térmico - Vedações & Sim & $\mathbf{X}$ & & & \\
\hline $\begin{array}{l}\text { 2.8 Desempenho Térmico - Orientação ao Sol e } \\
\text { Ventos }\end{array}$ & Sim & $\mathbf{X}$ & & & \\
\hline 2.9 Iluminação Natural de Áreas Comuns & & $\mathbf{X}$ & & & \\
\hline 2.10 Vent. e Ilum. Natural de Banheiros & & & $\mathbf{X}$ & & \\
\hline 2.11 Adequação às Condições Físicas do Terreno & & $\mathbf{X}$ & & & \\
\hline \multirow{2}{*}{3 - EFICIENCIA ENERGÉTICA } & \multirow{2}{*}{$\begin{array}{l}\text { Obriga } \\
\text { torio }\end{array}$} & \multicolumn{4}{|c|}{ Existência no Projeto } \\
\hline & & Sim & Não & $\begin{array}{c}\text { Parcial } \\
\text { mente }\end{array}$ & $\begin{array}{l}\text { Não se } \\
\text { aplica }\end{array}$ \\
\hline $\begin{array}{l}\text { 3.1 Lâmpadas de Baixo Consumo - Áreas } \\
\text { Privativas } \\
\end{array}$ & $\begin{array}{l}\text { até } 3 \\
\text { S.m. }\end{array}$ & & $\mathbf{X}$ & & \\
\hline 3.2 Dispositivos Economizadores - Áreas Comuns & Sim & $\mathbf{X}$ & & & \\
\hline 3.3 Sistema de Aquecimento Solar & & & $\mathbf{X}$ & & \\
\hline 3.4 Sistemas de Aquecimento à Gás & & & $\mathbf{X}$ & & \\
\hline 3.5 Medição Individualizada - Gás & Sim & $\mathbf{X}$ & & & \\
\hline 3.6 Elevadores Eficientes & & & & & $\mathbf{X}$ \\
\hline 3.7 Eletrodomésticos Eficientes & & & & & $\mathbf{X}$ \\
\hline 3.8 Fontes Alternativas de Energia & & & $\mathbf{X}$ & & \\
\hline
\end{tabular}




\begin{tabular}{|c|c|c|c|c|c|}
\hline \multirow{2}{*}{4 - CONSERVAÇÃODE RECURSOS } & \multirow{2}{*}{$\begin{array}{l}\text { Obriga } \\
\text { torio }\end{array}$} & \multicolumn{4}{|c|}{ Existência no Projeto } \\
\hline & & Sim & Não & $\begin{array}{l}\text { Parcial } \\
\text { mente }\end{array}$ & $\begin{array}{l}\text { Não se } \\
\text { aplica }\end{array}$ \\
\hline 4.1 Coordenação Modular & & & & $\mathbf{X}$ & \\
\hline 4.2 Qualidade de Materiais e Componentes & Sim & $\bar{X}$ & & & \\
\hline $\begin{array}{l}\text { 4.3 Componentes Industrializados ou Pré- } \\
\text { fabricados } \\
\end{array}$ & & & & $\mathbf{X}$ & \\
\hline 4.4 Formas e Escoras Reutilizáveis & Sim & $\mathbf{X}$ & & & \\
\hline 4.5 Gestão de Resíduos de Construção e Demolição & Sim & $\mathbf{X}$ & & & \\
\hline 4.6 Concreto com Dosagem Otimizada & & $\bar{X}$ & & & \\
\hline $\begin{array}{c}\text { 4.7 Cimento de Alto-Forno CPIII e Pozolânico CP } \\
\text { IV }\end{array}$ & & $\mathbf{X}$ & & & \\
\hline 4.8 Pavimentação com RCD & & & $\mathbf{X}$ & & \\
\hline 4.9 Facilidade de Manutenção da Fachada & & $\mathbf{X}$ & & & \\
\hline 4.10 Madeira Plantada ou Certificada & & $\mathbf{X}$ & & & \\
\hline \multirow[b]{2}{*}{5 - GESTÃO DA ÁGUA } & \multirow{2}{*}{$\begin{array}{c}\text { Obriga } \\
\text { torio }\end{array}$} & \multicolumn{4}{|c|}{ Existência no Projeto } \\
\hline & & Sim & Não & $\begin{array}{c}\text { Parcial } \\
\text { mente }\end{array}$ & $\begin{array}{l}\text { Não se } \\
\text { aplica }\end{array}$ \\
\hline 5.1 Medição Individualizada - Água & Sim & $\mathbf{X}$ & & & \\
\hline $\begin{array}{c}5.2 \text { Dispositivos Economizadores - Sistema de } \\
\text { Descarga obrigatório }\end{array}$ & & $\mathbf{X}$ & & & \\
\hline 5.3 Dispositivos Economizadores - Arejadores & & & & $\mathbf{X}$ & \\
\hline 5.4 Dispositivos Economizadores & & & $\mathbf{X}$ & & \\
\hline 5.5 Aproveitamento A. pluviais & & & $\mathbf{X}$ & & \\
\hline 5.6 Retenção de Águas Pluviais & & & $\mathbf{X}$ & & \\
\hline 5.7 Infiltração de Águas Pluviais & & & $\mathbf{X}$ & & \\
\hline 5.8 Áreas Permeáveis & Sim & $\underline{X}$ & & & \\
\hline \multirow[b]{2}{*}{6 - PRÁTICAS SOCIAIS } & \multirow{2}{*}{$\begin{array}{c}\text { Obriga } \\
\text { torio }\end{array}$} & \multicolumn{4}{|c|}{ Existência no Projeto } \\
\hline & & Sim & Não & $\begin{array}{c}\text { Parcial } \\
\text { mente }\end{array}$ & $\begin{array}{l}\text { Não se } \\
\text { aplica }\end{array}$ \\
\hline 6.1 Educação para a Gestão de RCD & Sim & & $\mathbf{X}$ & & \\
\hline 6.2 Educação Ambiental dos Empregados & Sim & & $\mathbf{X}$ & & \\
\hline 6.3 Desenvolvimento Pessoal dos Empregados & & & $\mathbf{X}$ & & \\
\hline 6.4 Capacitação Profissional dos Empregados & & $\mathbf{X}$ & & & \\
\hline 6.5 Inclusão de trabalhadores locais & & $\mathbf{X}$ & & & \\
\hline $\begin{array}{l}\text { 6.6 Participação da Comunidade na Elaboração do } \\
\text { Projeto } \\
\end{array}$ & & $\mathbf{X}$ & & & \\
\hline 6.7 Orientação aos Moradores & Sim & $\mathbf{X}$ & & & \\
\hline 6.8 Educação Ambiental dos Moradores & & & $\mathbf{X}$ & & \\
\hline 6.9 Capacitação para Gestão do Empreendimento & & & $\mathbf{X}$ & & \\
\hline 6.10 Ações para Mitigação de Riscos Sociais & & $\mathbf{X}$ & & & \\
\hline 6.11 Ações para a Geração de Emprego e Renda & & & $\mathbf{X}$ & & \\
\hline
\end{tabular}

Fonte: Mariana Veras (2013)

O projeto atendeu positivamente a 27 dos 53 critérios de análise do Selo Casa Azul, porém não seria certificado pelo fato de não atender a dois obrigatórios: a educação para a gestão de resíduos sólidos e a educação ambiental dos empregados na obra.

Todos os critérios foram avaliados individualmente em função dos parâmetros técnicos e científicos descritos no Manual do Selo Casa Azul, por exemplo, para o critério de iluminação natural foram elaboradas simulações para a constatação da qualidade, com o emprego do software Relux Professsional 2000 e posteriori constatação no local, cujo resultado é apresentado na figura 7.(VERAS, 2013) 
Figura 7 - Distribuição da iluminância interna em pseudo cores no pavimento tipo.

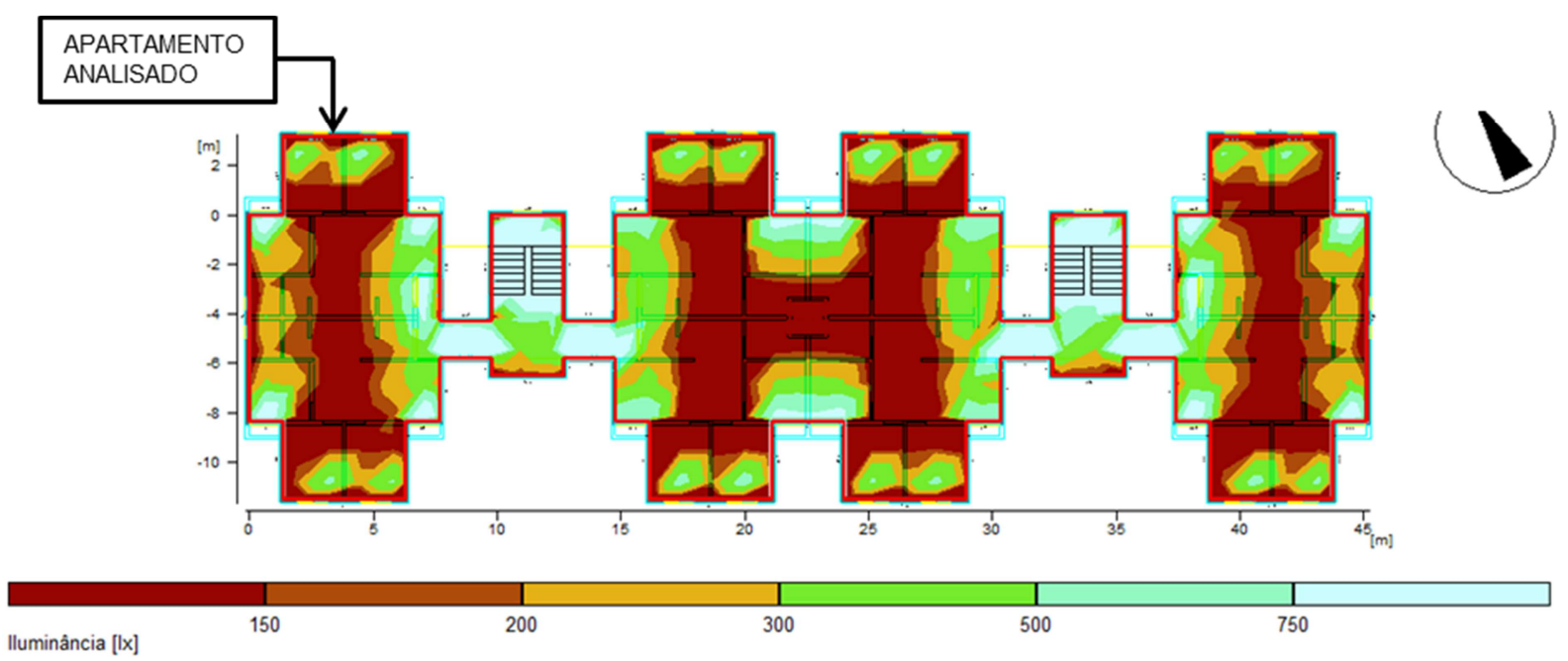

Fonte: Veras (2013, p. 60).

Após a conclusão desta pesquisa (em fevereiro de 2013) o Selo Casa Azul passou por alterações, porém esta pesquisa foi elaborada apoiada na versão elaborada em 2010, que ficou em vigor até fevereiro de 2013. As mudanças ocorridas ocorreram porque os critérios do Selo Casa Azul se tornaram mais restritivos que os da norma de desempenho habitacional (ABNT NBR 15575) aprovada em 2013 e ao Procel Edifica Residencial. Desta maneira foi realizada uma revisão nos indicadores, com o objetivo de atualizar e adequar a metodologia às normas e diretrizes voltadas à elaboração de projetos habitacionais. Outra alteração foi a criação do "Critério Bônus", que contará como um critério de livre escolha, consentindo uma pontuação a mais na avaliação do projeto, a partir da inclusão de outras medidas que não foram contempladas na lista proposta, desde que analisados e aprovados antecipadamente pela CAIXA. (CAIXA ECONÔMICA FEDERAL, 2014)

\section{CONSIDERAÇÕES FINAIS}

Perante a análise realizada a partir de dados coletados sobre o Conjunto Habitacional Mata Virgem, observa-se muitos aspectos positivos com a instalação desse empreendimento no local. Dentre eles pode-se citar a melhoria no entorno imediato, a instalação de infraestrutura básica, a geração de emprego aos moradores locais e as parcerias entre Prefeitura e Estado. Outras questões poderiam ter sido incluídas no projeto, como por exemplo, o aproveitamento de águas pluviais e sistemas de aquecimento de água por energia solar ou a gás.

O Conjunto Mata Virgem se submetido a avaliação da versão inicial Selo Casa Azul da CAIXA não receberia certificação nos critérios analisados, porém a obra apresenta o projeto e construção que se destacam pela boa arquitetura, em relação aos projetos recorrentes de conjuntos habitacionais de interesse social. 
Este trabalho, juntamente com as demais pesquisas desenvolvidas pelo grupo Arquitetura e Construção da Faculdade de Arquitetura e Urbanismo da Universidade Presbiteriana Mackenzie, através da aplicação de metodologia semelhante, compõem uma análise crítica sobre os conjuntos de habitação social contemporâneos na cidade de São Paulo. Os resultados dessas pesquisas alimentam o repertório pré-existente e incentivam o desenvolvimento de novos estudos, além de poderem ser empregados como parâmetros para a fundamentação de novos processos de projetos de habitação de interesse social.

\section{AGRADECIMENTOS}

Ao CNPq e a CAPES pelo apoio recebido e ao Arquiteto José Luiz Tabith Junior por ter permitido o emprego de seu acervo pessoal.

\section{REFERÊNCIAS}

ASSOCIAÇÃO BRASILEIRA DE NORMAS TÉCNICAS - ABNT NBR 15575-5_2013 Edificações habitacionais - Desempenho, 2013.

BOAS PRÁTICAS PARA HABITAÇÃO MAIS SUSTENTÁVEL / coordenadores Vanderley Moacyr John, Racine Tadeu Araújo Prado. -- São Paulo: Páginas \& Letras - Editora e Gráfica, 2010.

CAIXA ECONÔMICA FEDERAL. Veja o que mudou no selo Casa Azul. Disponível em: http://downloads.caixa.gov.br/_arquivos/sustent/selo_casa_azul/Mudancas_Selo_Casa_Azul.pdf Acesso em 09 abr. 2014.

PISANI, Maria Augusta Justi ET AL. Habitação Social no Brasil: projetos e sustentabilidade no século XXI. Relatório de pesquisa. São Paulo, Mackpesquisa, 2013.

SÂO PAULO (município). Prefeitura do Município de São Paulo (PMSP). Secretaria municipal de Habitação (SEHAB). Programas: Programa Mananciais. Disponível em: $<$ http://www.prefeitura.sp.gov.br/cidade/secretarias/habitacao/programas/index.php?p=3377>.

Acesso em: 26 nov. 2012

SÂO PAULO (município). Prefeitura do Município de São Paulo (PMSP). Plano Municipal de Habitação. São Paulo. 2010.

SÂO PAULO (município). Prefeitura do Município de São Paulo. Secretaria de Habitação e Desenvolvimento urbano. Urbanização de favelas: a experiência de São Paulo. São Paulo: Boldarini Arquitetura e urbanismo, 2008.

SÂO PAULO (município). Secretaria de Estado da Habitação. Companhia de Desenvolvimento Habitacional e Urbano. Plano Plurianual - PPA 2008-2011. 2012?. Disponível em: $<$ http://www.habitacao.sp.gov.br/secretariahabitacao/downloads/plano-plurianual.pdf $>$. Acesso em: 25 mai. 2013.

VERAS, Mariana Ribeiro. Sustentabilidade e habitação de interesse social na cidade de são Paulo: análise de obras. Dissertação de Mestrado apresentada a Faculdade de Arquitetura e Urbanismo da Universidade P. Mackenzie, São Paulo: 2013. 